\title{
Microstructure and Properties of Peg-nail Structured YSZ TBCs by Selective Laser Modification after Plasma Spraying
}

\author{
Chang $\mathrm{Fa}^{1,2,3}$, Zhou Kesong ${ }^{1,2,3}$, Tong $\mathrm{Xin}^{2,3}$, Wang $\mathrm{JiaO}^{2,3}$, Liu Min ${ }^{2,3}$, Kang \\ Zhongmin $^{2,3}$
}

${ }^{1}$ South China University of Technology, Guangzhou 510640, China; ${ }^{2}$ Guangzhou Research Institute of Non-ferrous Metals, Guangzhou 510651, China; ${ }^{3}$ Guangdong Provincial Key Laboratory of Modern Surface Engineering Technology, Guangzhou 510651, China

\begin{abstract}
Yttria partially stabilized zirconia (YSZ) thermal barrier coatings (TBCs) were deposited by an air plasma spraying (APS) method on nickel-based superalloy with initially sprayed NiCoCrAlYTa bond coat. After that, the surface of the plasma sprayed TBCs was subjected to selective laser modification using a Nd:YAG pulsed laser. The microstructure and performance of the plasma sprayed and peg-nail structured YSZ coatings by selective laser modification were investigated. The results reveal that selective laser modification helps to reduce the surface roughness considerably, eliminate surface porosities and produce a network of continuous cracks perpendicular to the surface. The microstructure of peg-nail structured units consists of columnar grains in the cross-section and equiaxed grains on the surface. XRD patterns show that both as-sprayed and the peg-nail structured coatings by selective laser modification consist of nonequilibrium tetragonal $\left(\mathrm{T}^{\prime}\right)$ phase; however, monoclinic $(\mathrm{M})$ phase disappeared and intensity of $\mathrm{T}^{\prime}$ phase slightly increases in the range of $72^{\circ} \sim 76^{\circ}(2 \theta)$ after selective laser modification. It has been found that the average bonding strength YSZ coatings is enhanced from 7.3 MPa to 13.3 MPa after selective laser modification. Thermal insulation capability of the peg-nail structured YSZ coating by selective laser modification, as compared to the as-sprayed YSZ coating, is decreased due to microstructure change in the ceramic top coat.
\end{abstract}

Key words: YSZ; peg-nail structure; laser modification; bonding strength; thermal insulation capability

The yttria stabilized zirconia (YSZ) belonging to oxide ceramic materials features high melting temperature, good chemical stability, high thermal expansion coefficient and low thermal conductivity in comparison with other ceramic materials ${ }^{[1]}$. Thus it is usually chosen as the top coat material of thermal barrier coatings (TBCs), which produces advantages of increased operating temperature and efficiency subsequently ${ }^{[2,3]}$. Currently, a typical TBCs system includes MCrAlY $(M=\mathrm{Co}$ and/or Ni) metallic bond coat as the intermediate oxidation resistant layer and a zirconia based ceramic top coat as the thermal insulation layer ${ }^{[4,5]}$. The metallic bond coat deposited on the superalloy substrate is to protect the underlying metal from oxidation and to enhance adherence between the substrate and the top coat ${ }^{[6]}$. The ceramic top coat behaves as an insulation layer to reduce the temperature of the underlying superalloy in relation to the gas path temperature ${ }^{[7]}$.

Nowadays, the most widely used method of depositing ceramic coating is either air plasma spraying (APS) with a splat structure or electron beam physical vapor deposition (EB-PVD) with a columnar structure ${ }^{[8,9]}$. TBCs deposited by APS method features pores, cracks with parallel and normal orientation to substrate as well as other defects which lowers the adhesion and strengthens the coating peeling. These mentioned defects facilitate diffusion permeability of oxygen ions from gas medium through YSZ ceramic top coat and into bond coat where the thermally grown oxide (TGO) was formed $^{[10]}$. The growth of TGO during operations at high

Received date: March 25, 2016

Foundation item: National Key Basic Research Development Program of China (“973 Program”) (2012CB625100); Fundamental Research Funds of GGRIIT (1043113) Corresponding author: Chang Fa, Ph. D., School of Materials Science and Engineering, South China University of Technology, Guangzhou 510640, P. R. China, E-mail: cfzyzs_2011@163.com

Copyright $($ C 2017, Northwest Institute for Nonferrous Metal Research. Published by Elsevier BV. All rights reserved. 
temperatures which induces structural stresses and cracks leads to the failure of the TBCs system by spallation of the ceramic top coat when it is up to the critical level ${ }^{[5,11]}$.

Previous several studies ${ }^{[12,13]}$ demonstrate that laser glazing is currently recognized as a high promising technique for improvement of plasma sprayed TBCs performance and extension of their lifetime. Laser surface treatment of TBCs is often associated with reducing surface roughness, free from porosity but with formation of a controlling segmented crack perpendicular to the surface ${ }^{[14,15]}$. Nevertheless, because of the inherent disadvantages of laser glazing, such as generating a high level of residual stresses in the whole coating and never improvement of bond strength between ceramic coat and bond coat, these factors will restrict the application of laser glazing technique in ceramic coatings field.

To overcome the inherent disadvantages of laser glazing TBCs and to improve TBCs performance, one way is to modify the coating architecture by an adapted manufacturing process. To reach this goal, an innovative laser process, defined as selective laser modification in this study, is implemented on TBCs by a pulsed Nd:YAG laser. The selective laser modification is that laser discontinuously remelts the part region of the coating. The purpose of selective laser modification is to create a peg-nail structure. The characteristics of selective laser modification to create a peg-nail structure is distinct from the remelting whole coating by laser glazing or laser remelting. The peg-nail structure is that the laser modified region impenetrates ceramic top coat and partial bond coat, remelting and rapid resolidification occurs in these sections, and then cross sectional profile like inverse parabolic peg-nail forms during laser modification $^{[16,17]}$, the laser modified region is named peg-nail structured unit in coating.

In this work, the aim is to acquire a better understanding of change in the surface morphology, microstructure and phase transformation of peg-nail structured YSZ coatings by selective laser modification. Also, the bonding strength and thermal insulation capability of the peg-nail structured YSZ coating functioned as TBCs are further investigated.

\section{Experiment}

\subsection{TBCs manufacturing}

A nickel based superalloy ( $\mathrm{K}$ 4169) was employed as substrate with preparation $25.4 \mathrm{~mm}$ in diameter and $5 \mathrm{~mm}$ in thickness, whose chemical composition (wt\%) is: C 0.02 0.08, $\mathrm{Ni}$ 50.0 55.0, Cr 17.0 21.0, Mo 2.8 3.3, Al 0.3 0.7, Ti $0.65 \sim 1.15, \mathrm{Nb}+\mathrm{Ta} 4.4 \sim 5.4, \mathrm{Co} \leqslant 1.0, \mathrm{Mn} \leqslant 0.35, \mathrm{Si} \leqslant 0.35, \mathrm{Cu}$ $\leqslant 0.30, \mathrm{~S} \leqslant 0.015$ and balance $\mathrm{Fe}$. The substrates were grit blasted with $125 \mu \mathrm{m}$ zirconium corundum under a pressure of 0.25 0.30 MPa in order to increase adherence between the bond coat and the substrate, and then degreased and cleaned with acetone and preheated with plasma gun prior to deposition. The commercially available NiCoCrAlYTa powder (AMDRY 997,
Sulzer Metco Inc., USA, 15 45 $\mu \mathrm{m}$ ) with nominal composition (wt $\%$ ) of $\mathrm{Ni}-21 \mathrm{Cr}-22 \mathrm{Co}-8 \mathrm{Al}-0.6 \mathrm{Y}-4.5 \mathrm{Ta}$ was first deposited onto the surface of substrates as bond coat with a thickness of about $100 \mu \mathrm{m}$ by high velocity oxygen fuel (HVOF) system (K2, GTV, Germany), and then $\mathrm{ZrO}_{2}-7 \quad$ wt $\% \mathrm{Y}_{2} \mathrm{O}_{3}$ powder (AMPERIT 827.054, H. C. Starck, Germany, 10 45 $\mu \mathrm{m}$ ) was sprayed as top coat with a thickness of about $200 \mu \mathrm{m}$ by air plasma spraying (APS) system (MF-P-1000, GTV, Germany). Spraying conditions of the bond coat and the YSZ coatings are shown in Table 1 and Table 2, respectively.

\subsection{Laser parameters}

The selective laser modification was performed using a pulsed Nd:YAG laser (XL-600Y, Lambda Photometrics, Ltd.) with a mean power of $600 \mathrm{~W}$, a wavelength of $1.064 \mu \mathrm{m}$ and standard square shaped pulses. Processing parameters of the peg-nail structured laser modification experiment was optimized from an adequate number of preliminary experiments which are as follows: input current of $120 \mathrm{~A}$, pulse width of $2.2 \mathrm{~ms}$, pulse frequency of $7 \mathrm{~Hz}$ and laser spot diameter of $1 \mathrm{~mm}$. The selective region with definite spacing were remelted and resolidified after laser modification in each sample's surface by controlling the displacement of the 3-axis $\mathrm{CNC}$ workbench. Amounts of the discrete and regular peg-nail structured units were created on the surface of coating by selective laser modification, and the surface images of peg-nail structured coating by selective laser modification are shown in Fig.1.

\subsection{Coating structure characterization}

The surface morphology of the as-sprayed and the peg-nail structured coatings by selective laser modification was observed using a stereomicroscope (XTL-2400, Shenzhen Mingda Technology Company, Ltd.). The samples for transverse section microstructure and chemical compositions were observed and determined by a scanning electron microscope (SEM, JSM-5910, JEOL Ltd., Japan) equipped

Table 1 Parameters of high velocity oxygen fuel (HVOF)

\begin{tabular}{cc}
\hline Parameter & NiCoCrAlYTa \\
\hline Spray distance $/ \mathrm{mm}$ & 350 \\
Kerosene $/ \mathrm{L} \cdot \mathrm{h}^{-1}$ & 25 \\
Oxygen $/ \mathrm{L} \cdot \mathrm{min}^{-1}$ & 900 \\
Chamber pressure $/ \times 10^{5} \mathrm{~Pa}$ & 8.4 \\
Powder feed rate $/ \mathrm{g} \cdot \mathrm{min}^{-1}$ & 50 \\
\hline
\end{tabular}

Table 2 Parameters of air plasma spraying (APS)

\begin{tabular}{cc}
\hline Parameter & YSZ \\
\hline Current/A & 650 \\
Voltage/V & 68 \\
Primary gas, Ar (SLPM*) & 40 \\
Secondary gas, H $_{2}(\mathrm{SLPM})$ & 9 \\
Carrier gas, Ar (SLPM) & 5 \\
Spray distance/mm & 110 \\
Powder feed rate/g. $\mathrm{min}^{-1}$ & 52 \\
\hline
\end{tabular}




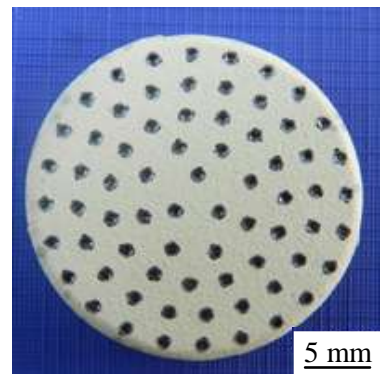

Fig.1 Surface morphology of the peg-nail structured YSZ coating by selective laser modification

with energy dispersion spectroscopy (EDS).

Phase compositions of the as-sprayed and the peg-nail structured coatings by selective laser modification were investigated by a X-ray diffractometer (XRD, D/max-IIIA, Philips Ltd., Netherlands) (45 kV, $40 \mathrm{~mA}, \mathrm{Cu} \mathrm{K} \alpha$ radiation with $\lambda=0.15444 \mathrm{~nm})$. A $2 \theta$ scanning rate of $0.02^{\circ} / \mathrm{s}$ and a measuring time between each step of $6.0 \mathrm{~s}$ was employed to determinate the peak positions of the different $\mathrm{ZrO}_{2}-\mathrm{Y}_{2} \mathrm{O}_{3}$ phase in the range of $20^{\circ}<2 \theta<90^{\circ}$. The region of the (004) and (400) $\mathrm{T}^{\prime}$ metastable phase peaks, between $72^{\circ}$ and $76^{\circ}$, was especially investigated with a scanning rate of $0.01 \%$ and a measuring time between each step of $60 \mathrm{~s}$.

\subsection{Coating properties}

\subsubsection{Tensile adhesion test}

The bonding strength test was employed to study the bond strength of the YSZ TBCs according to the GB 5210-85 (ISO 4624) standard. A disk-shaped ${ }^{[18]}$ TBCs coated specimen was bonded to two loading fixtures of $25.4 \mathrm{~mm}$ diameter using a strong epoxy adhesive (FM1000, CYTEC Ltd., USA). This adhesive was cured under a pressure of $35 \mathrm{~N}$ for $3 \mathrm{~h}$ at $190{ }^{\circ} \mathrm{C}$, then cooling down to room temperature in an electric furnace. The direct pull test was applied by an electronic universal testing machine (GP-TS 2000M, GOPOINT TESTING EQUIPMENT CO., Ltd, China). A constant cross head displacement rate of $0.101 \mathrm{~cm} / \mathrm{min}$ was employed. For each kind of TBCs systems, and three samples were subjected to the adhesion strength test.

\subsubsection{Thermal insulation capability test}

In order to evaluate thermal insulation value of TBCs, the thermal insulation capability test was carried out by a selfdeveloped device, and the schematic illustration is shown in Fig.2. To eliminate the effect of temperature drop by substrate, the substrate backside was cooled by compress air, and the substrate without TBCs was acted as the reference sample. Thus, the substrate with TBCs samples including the assprayed and the laser modified coatings was fixed in the set-up in turn, and was heated by the oxygen-propane flame. An infrared thermometer and a thermocouple were used as sensors. The infrared thermometer was used to monitor the specimen surface temperature $\left(T_{0}\right)$. The thermocouple was

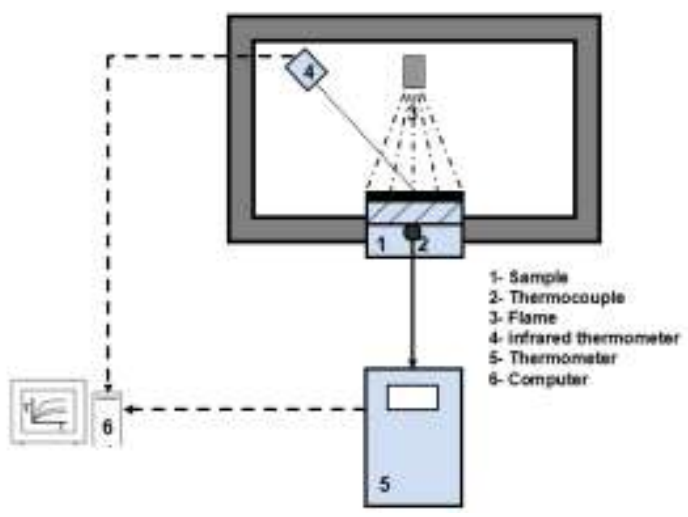

Fig.2 Schematic illustration of the thermal insulation capability test

fixed in the sample backside to monitor the backside temperature of the samples $\left(T_{x}, x=1,2,3 \cdots\right)$. The thermocouple was linked to a thermometer and then to a computer to record the heating temperatures. The samples were heated from $25^{\circ} \mathrm{C}$ to $1150{ }^{\circ} \mathrm{C}$ in $120 \mathrm{~s}$. To stabilize temperature conditions, the specimens were kept at $1150{ }^{\circ} \mathrm{C}$ for $300 \mathrm{~s}$. $T_{0}$ and $T_{x}$ were recorded from the beginning of the test in four second time intervals and $t-T$ curves were plotted by computer. The thermal insulation capability by the temperature drop across TBC was calculated.

\section{Results and Discussion}

\subsection{Surface morphology and microstructure}

From visual inspection in Fig.1, no spallation on the pegnail structured coating can be observed. The peg-nail structured units are discrete distribution on the coating surface.

Fig.3 presents the surface morphology of peg-nail structured unit. It can be observed that the peg-nail structured unit surface is distinct from as-sprayed surface. The peg-nail structured unit consists of a completely resolidified surface and a segment of continuous cracks. The segmented cracks are propagated to the vertical direction from the surface. Without any doubt, the segmented cracks are attributed to shrinkage and relaxation of thermal stresses during the rapid and nonuniform cooling of molten zirconia and probably to localized temperature gradient which generates residual

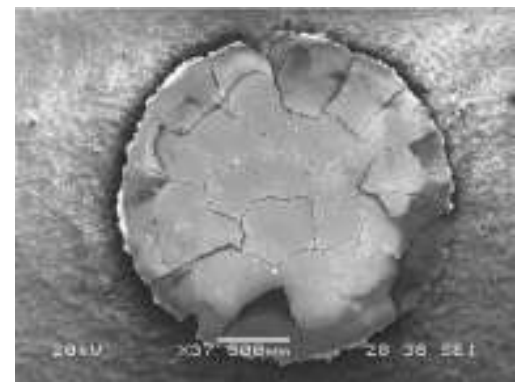

Fig.3 Surface micrograph of the peg-nail structured unit 
stresses after laser modification ${ }^{[14,15]}$. The formation of segmented cracks in peg-nail structure units is expected to be beneficial to accommodating of the oxidation stress, mismatch stress, and improving of thermal shock resistance of TBCs ${ }^{[15]}$.

Fig. 4 depicts, on the left side, three-dimensional surface maps of coatings on the as-sprayed and the peg-nail structured units by selective laser modification. On the right side are SEM micrographs of the same coatings surface. It can be seen that a dissimilar morphology appears with a substantial difference in roughness for the two specimens. Fig.4a shows that top surface of the as-sprayed coating is very rough because of partially molten particles involved in low deformation as compared to fully molten particles ${ }^{[18-20]}$. Tortuous microcracks, pores and protrusions are also identifiable and exhibit a very irregular profile. On the surface map of the peg-nail structured units (Fig.4b), the axis normal to the coating plane is a considerably flat profile and the surface roughness is reduced evidently. As can be seen in Fig.4b, all the principal characteristics in as-sprayed microstructure TBCs such as cracks, voids, porosity, protrusion, partially melted particles and non-melted particles vanish after laser modification. The surface of the peg-nail structured units becomes smooth. In laser modification process, the combination effects of the temperature gradient, surface tension forces and the gravity forces result in the reduction of surface roughness ${ }^{[10,21]}$. According to the previous studies ${ }^{[22,23]}$, the reduction of surface roughness helps improvement of the erosion resistance and hot salt corrosion lifetime.
Fig.5 shows the transverse section morphologies of assprayed coating and the peg-nail structured units by selective laser modification. As shown in Fig.5a, it can be seen that different layers of usual TBCs can be observed which include NiCoCrAlYTa bond coat and YSZ top coat, and the interface between them is visible. Also, the microcracks, voids and porosities in the top coat are evident. The formation of these defects is owing to random deposition associated with residual stresses, insufficient overlap of adjacent splats and gas entrapment and escape during deposition process ${ }^{[19]}$. The transverse sectional profile of the peg-nail structured unit by selective laser modification, shown in Fig.5b, is similar to the inverse parabola. The whole YSZ top coat and partial NiCoCrAlYTa bond coat is impenetrated. The microstructure of the YSZ top coat in peg-nail structured units exhibits dense columnar grains. The interface between the bond coat and the top coat becomes indistinguishable in SEM due to remelting and resolidification during laser modification. According previous study ${ }^{[17]}$, the selective laser modification results in partial metallurgical bond at interface between the bond coat and the top coat in the peg-nail structured unit.

High magnification micrograph of the peg-nail structured unit by selective laser modification is shown in Fig.6. The microstructure of the peg-nail structured unit is homogeneous. Remelted surface by rapid melting and solidification is a dense modified layer. The microstructure of the peg-nail structured unit changes from lamellar to columnar due to the direction of the heat flow from cooling down to room temperature ${ }^{[12]}$. It is
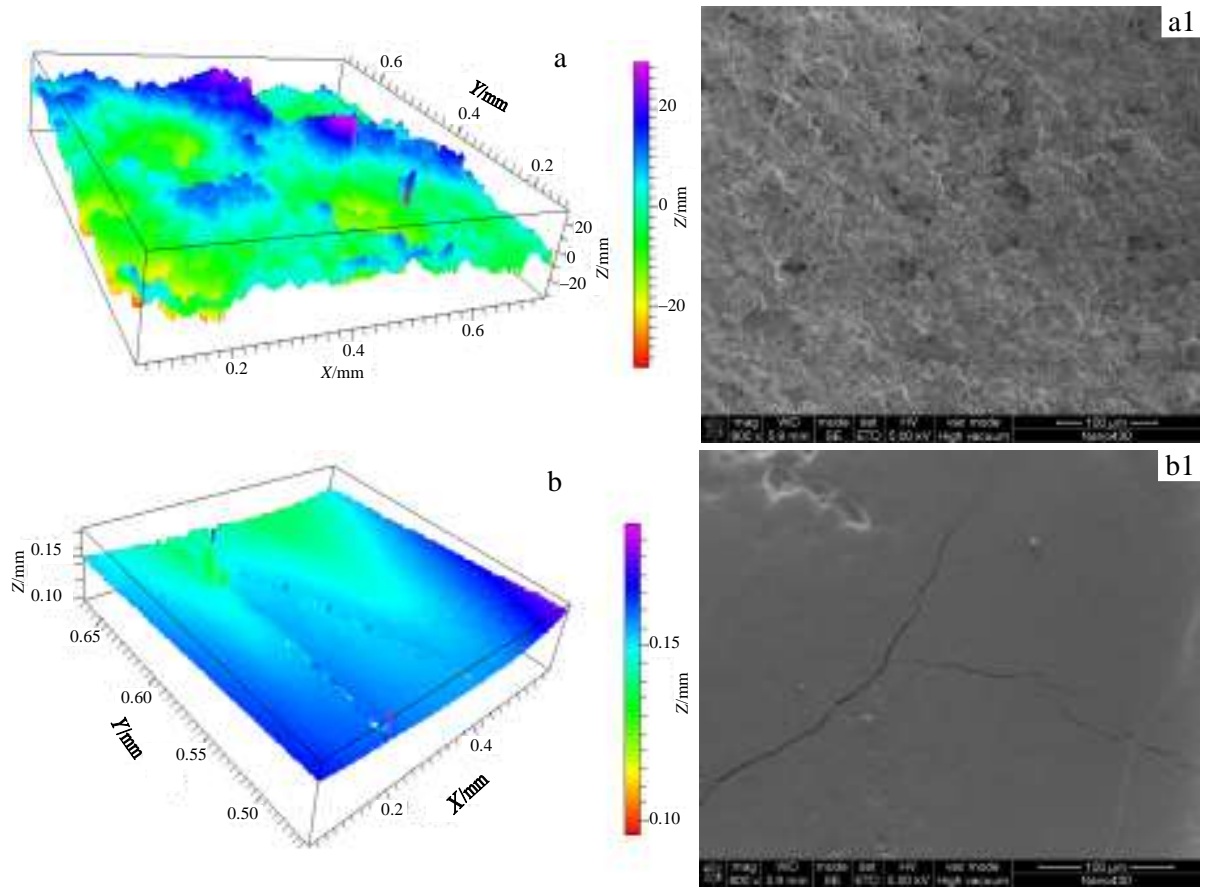

Fig.4 Three-dimensional maps $(a, b)$ and SEM micrographs $\left(a_{1}, b_{1}\right)$ of the surface of as-sprayed YSZ coating $\left(a, a_{1}\right)$ and the peg-nail structured YSZ coating by selective laser modified $\left(b, b_{1}\right)$ 


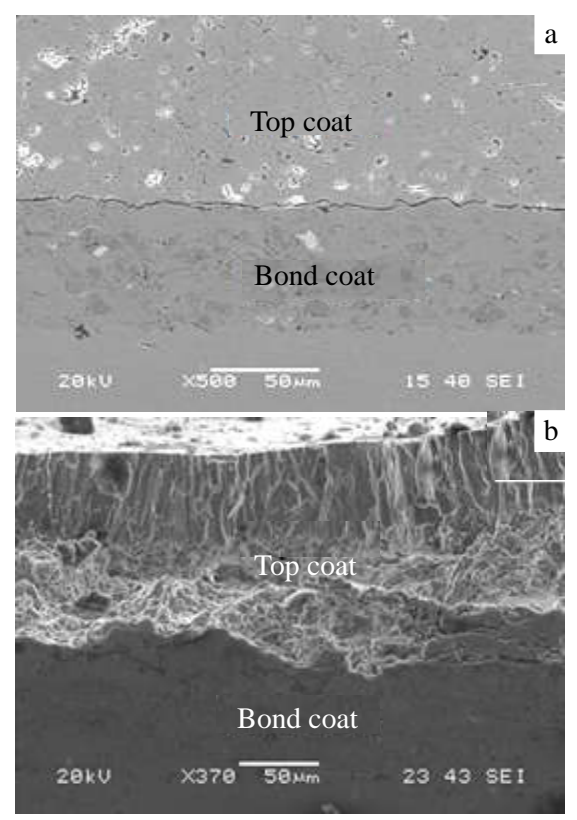

Fig.5 SEM micrographs of transverse section of TBCs: (a) assprayed coating and (b) peg-nail structured unit by selective laser modification

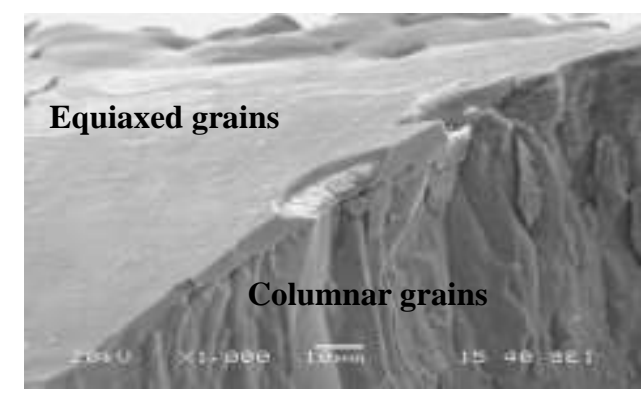

Fig. 6 High magnification SEM micrograph of the peg-nail structured unit by selective laser modification

noted that a thin discontinuous coarse equiaxed grain is nucleated on surface of columnar grains and grows inward ${ }^{[24]}$. The columnar grain is more helpful in increasing operation stress and strain ${ }^{[13]}$.

\subsection{Structural analysis and phase transformation}

XRD patterns of the as-sprayed and the peg-nail structured coatings by selective laser modification are shown in Fig.7. As can be seen, the tetragonal, cubic and monoclinic main characteristic peaks of zirconia are detected in $2 \theta$ range from $20^{\circ}$ to $90^{\circ}$. It demonstrates a tetragonal structure where the main diffraction peak is $\mathrm{T}^{\prime}$ (111) phase for both coatings. In Fig.7, all of the peaks with crystallographic asymmetry, e.g. (200), (113) and (400) show a more distinctive split after laser modification. Tetragonal phase gives split peaks while the cubic does not. Fig.8 represents the diffraction patterns in (111) region, in which the monoclinic (M) phase is found in the

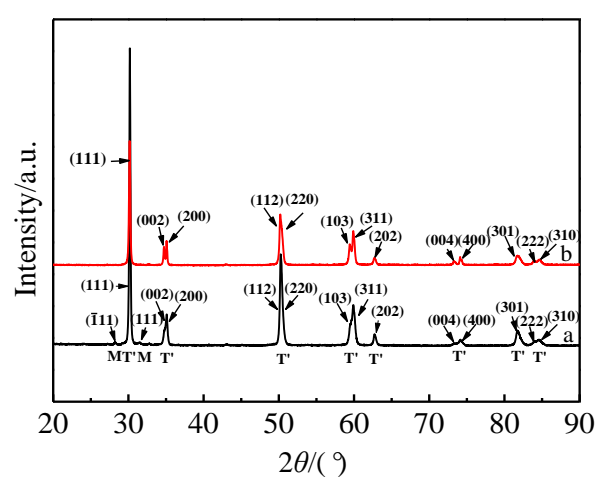

Fig. 7 XRD patterns in the entire range (a: as-sprayed YSZ coating, b: peg-nail structured YSZ coating by selective laser modification)
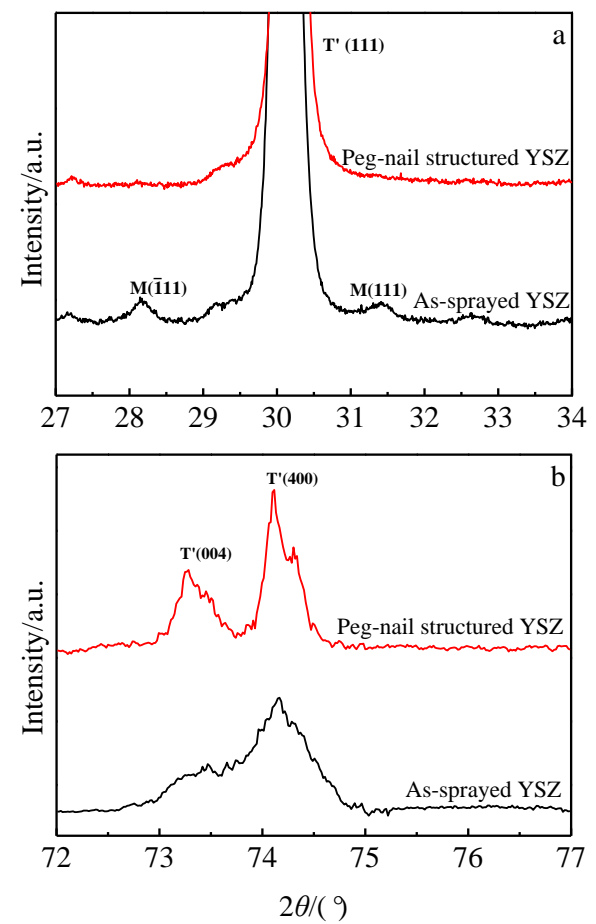

Fig.8 XRD patterns of the samples: (a) (111) region and (b) (400) region corresponding to Fig. 7

as-sprayed coating, while it is absent in the peg-nail structure laser modified unit. The as-sprayed coating exhibits a small amount of monoclinic phase deriving probably from partially melted particles with local in homogeneity in compositional distribution. The volume fraction of monoclinic phase is estimated to be approximately $2 \%$ calculated by the peak intensity ratio $(M)$ formula ${ }^{[16]}$ :

$$
M=\frac{I_{M}(\overline{1} 11)+I_{M}(111)}{I_{M}(\overline{1} 11)+I_{M}(111)+I_{T}(111)} \times 100 \%
$$

where $I$ represents the diffraction intensity of the respective lattice planes.

The peg-nail structured unit by selective laser modification 
presents only $\mathrm{C}$ phase and $\mathrm{T}$ ' phase, and no monoclinic phase appear. This can be explained by a homogenization, during selective laser modification, of the chemical composition of the phases present in the as-sprayed coating. The cubic phase then formed, comprising the high yttria content, transforms to the $\mathrm{T}^{\prime}$ martensitic phase with the same composition by a diffusionless mechanism due to the rapid solidification and rapid cooling to room temperature ${ }^{[22]}$. The cooling rate of the splats during the plasma spraying process is estimated to be higher than $10^{7}{ }^{\circ} \mathrm{C} \cdot \mathrm{s}^{-1}$ and the estimated cooling rate of the laser glazing is about $10^{3} \sim 10^{4}{ }^{\circ} \mathrm{C} \cdot \mathrm{s}^{-1}{ }^{[14]}$. Furthermore, detailed comparison of the patterns in the range $72^{\circ} \sim 76^{\circ}$ (Fig.8) shows that the increasing intensity of the peak of $\mathrm{T}^{\prime}(004)$ in the peg-nail structured unit is due to the columnar grain orientation, which is caused by laser modification ${ }^{[15,25]}$.

\subsection{Adhesion performance}

The main reasons for failure of TBCs system by spallation of ceramic top coat are the oxidation of the bond coat and the thermal expansion mismatch. This means that the interface between the ceramic top coat and the bond coat or between the coating and the substrate, is relatively fragile under service conditions. However, a satisfactory adhesion is the first and intrinsic need for a good coating, the quality and further performance of TBCs are strongly dependent on the adhesion between the coating and the substrate as well as on the adhesion (or cohesion) between the bond coat and the ceramic top coat. Therefore, the bonding strength of coating is considered as one of the most significant index for evaluating the adhesion performance of TBCs.

In the present study, the bonding strength of YSZ coating was evaluated by tensile test. The results of the tensile test for bond strength of the as-sprayed coating and the peg-nail structured coating by selective laser modification are listed in Table 3. For the as-sprayed coating, the mean value of bond strength is 7.3 $\mathrm{MPa}$, and the maximum/ minimum value is 9 and $6 \mathrm{MPa}$, respectively. For the peg-nail structured coating, mean value of bond strength is $13.3 \mathrm{MPa}$, and the maximum/minimum value is 16 and $11 \mathrm{MPa}$, respectively. By comparison, the bonding strength is improved strongly.

In order to further understand the improvement on bonding strength, the failure coatings of YSZ systems after tensile tests are given in Fig.9. As can be seen, the failure of the assprayed coatings occurs at the interface between bond coat and top coat. However, the failure of the peg-nail structured coating occurs mostly at the interface between top coat and bond coat and partially inside top coat. Besides, the peg-nail structured coating was fractured with many small zones, which is attributed to the division functions caused by the peg-nail structure. This demonstrates that the peg-nail structured effect caused by selective laser modification is helpful in strengthening the adhesive ability between top coat and bond coat. The mechanism of peg-nail structured effect can be explained from these aspects. Firstly, the interface
Table 3 Bonding strength of the YSZ coating systems (MPa)

\begin{tabular}{cccc}
\hline Method & Maximum & Minimum & Mean \\
\hline As-sprayed & 9 & 6 & 7.3 \\
Peg-nail & 16 & 11 & 13.3 \\
\hline
\end{tabular}

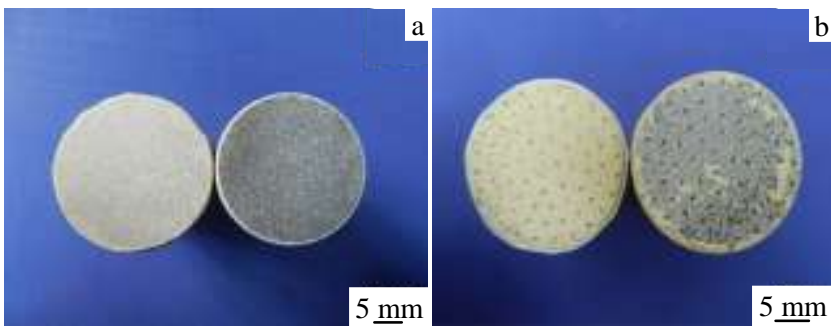

Fig.9 Fractured surfaces of YSZ TBCs systems after tensile tests: (a) as-sprayed coating and (b) peg-nail structured coating by selective laser modification

between top coat and bond coat in peg-nail structure unit generates a partial metallurgical bonding by selective laser modification, and the distribution of metallurgical bond dots in the peg-nail structured coating is the key factor, which is beneficial to improve the adhesive strength ${ }^{[16,17]}$. Secondly, an increase in bonding strength is attributed to segmented cracks and dendritic columnar created in the peg-nail structure units by selective laser modification. The presence of the vertical segmented cracks and columnar grain can be used effectively to relieve the thermal misfit stresses of the deposited coating on cooling ${ }^{[14]}$. Besides, the absence of $\mathrm{M}$ phase in peg-nail structured unit also eliminates to some degree the detrimental factors affecting the performance of peg-nail structured YSZ coating ${ }^{[5]}$. Due to these, the adhesion performance of peg-nail structured coating is improved.

\subsection{Thermal insulation capability}

The fundamental function of the TBCs is to reduce the transfer of thermal energy to the hot section of metal components. Therefore, the thermal insulation capability is considered as one of the most significant factors to evaluate the performance of the TBCs. In this investigation, the thermal insulation capability of YSZ coating was evaluated by temperature drop across TBCs $\left(\Delta T=T_{x}-T_{1}, x=2,3\right)$.

Fig.10 illustrates the recorded heating temperature curves of specimen surface $\left(T_{0}\right)$, the substrate backside $\left(T_{1}\right)$, substrate with YSZ backside $\left(T_{2}\right)$ and substrate with laser modified YSZ backside $\left(T_{3}\right)$. From this figure, it can be seen that $T_{1}, T_{2}$ and $T_{3}$ increase with the enhancement of specimen surface temperature $T_{0}$. As can be seen, thermal insulation capability for the as-sprayed and the peg-nail structured YSZ coating by selective laser modification is $85{ }^{\circ} \mathrm{C}$ and $72{ }^{\circ} \mathrm{C}$, respectively. That is to say, the $\Delta T$ value at $1150{ }^{\circ} \mathrm{C}$ of the peg-nail structured YSZ coating by selective laser modification is decreased by $18 \%$ compared with that of the as-sprayed YSZ 


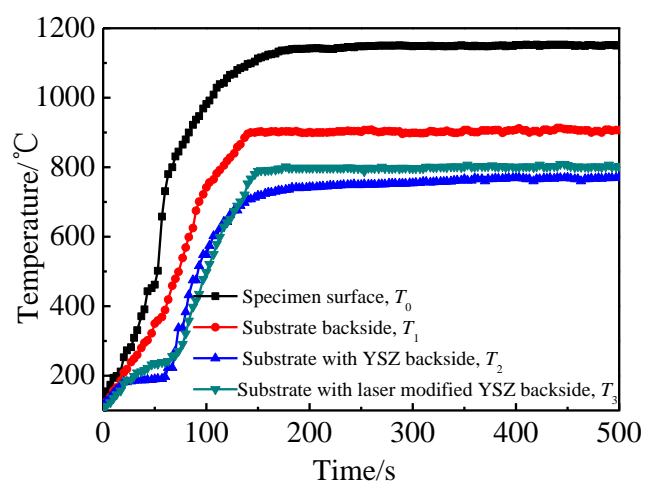

Fig.10 Heating temperature curves of the substrate and YSZ coatings

coating. It means that the peg-nail structured YSZ coating by selective laser modification has lower thermal insulation capability than the as-sprayed YSZ coating.

Generally, in the ceramic materials, the thermal insulation capability depends on the crystal structure and microstructure features, which result from the spraying process ${ }^{[9,26]}$. The microstructure of plasma sprayed coating contains a network of microcracks parallel to the surface and inter-splat pores, which provide a high impedance to heat flow through the thickness of the coating resulting in low thermal conductivity ${ }^{[27,28]}$. On the other hand, the lattice vibration controls thermal conductivity by hindering the transportation of phonons. So adding stabilizers to the crystal structure of zirconia creates the $\mathrm{O}_{2}$ vacancies and local strain fields in the lattice structure. These vacancies and strain fields effectively increase phonon scattering in the lattice ${ }^{[2,19]}$.

In the peg-nail structured YSZ coating by selective laser modification, the lamellar structure of ceramic top coat, including microcracks and porosities, is changed into compound structure with lamellar and dense columnar as well as segmented microcracks in peg-nail structure unit perpendicular to the plane of the coating. The decrease in porosities, microcracks accompanying columnar structure in laser modified coating increases apparent thermal conductivity. Therefore, a little reduction in thermal insulation capability of the peg-nail structured YSZ coating by selective laser modification is attributed to this microstructure change, which is the most effective reason for improvement of thermal shock resistance of YSZ coating.

\section{Conclusions}

1) The selective laser modification reduces the surface roughness considerably, eliminates the porosity of the surface and produces segmented cracks perpendicular to surface; the structure exhibits dendritic columnar in the peg-nail structured units.

2) The selective laser modification eliminates the monoclinic (M) phase and causes a metastable tetragonal phase more stably in the peg-nail structured units.

3) The mean value of bonding strength for the peg-nail structured YSZ coating by selective laser modification is 13.3 $\mathrm{MPa}$, and it is increased by about $82 \%$ of plasma sprayed YSZ coating compared with 7.3 MPa.

4) The peg-nail structured YSZ coatings by selective laser modification show a slightly lower thermal insulation capability than the as-sprayed coatings due to the microstructure change in coating from lamellar to columnar.

\section{References}

1 Huang H J, Wang M C. Ceramic International[J], 2013, 39: 1729

2 Cao X Q. Material of Thermal Barrier Coating[M]. Beijing: Science Press, 2007: 23 (in Chinese)

3 Keyvani A, Saremi M, Sohi Heydarzadeh M et al. Journal of Alloy and Compound[J], 2012, 541: 488

4 Girolamo G D, Blasi C, Pagnotta L et al. Ceramic International [J], 2010, 36: 2273

5 Antou G, Montavon G, Hlawka F et al. Journal of European Ceramic Society[J], 2006, 26: 3583

6 Wang L, Wang Y, Sun X G et al. Ceramic International[J], 2012, 38(5): 3595

7 Li Y, Xie Y, Huang L et al. Ceramic International[J], 2012, 38(6): 5113

8 Steinbrech R W, Postolenko V, Monch J et al. Ceramic International[J], 2011, 37: 363

9 Pidani R A, Razavi R S, Mozafarinia R et al. Ceramic International[J], 2013, 39: 2473

10 Krystyna K S. Journal of Alloy and Compound[J], 2010, 505: 516

11 Busso E P, Qian Z Q, Taylor M P et al. Acta Material[J], 2009, 57: 2349

12 Jasim K M. Journal of King Saud University Engineer Science[J], 2013, 25: 11

13 Morks M F, Berndt C C, Durandet Y et al. Apply Surface Science $[\mathrm{J}], 2010,256: 6213$

14 Batista C, Portinha A, Ribeiro R M et al. Surface and Coatings Technology[J], 2006, 200: 6783

15 Batista C, Portinha A, Ribeiro R M et al. Apply Surface Science [J], 2005, 247: 313

16 Tong X, Zhou K S, Chang F et al. Lasers in Engineering $[\mathrm{J}]$, 2015, 30(1-2): 129

17 Chang $\mathrm{Fa}$, Zhou Kesong, Tong Xin et al. Apply Surface Science[J], 2014, 317: 598

18 Girolamo G D, Marra F, Blasi C et al. Ceramic. International[J], 2011, 37: 2711

19 Jamali H, Mozafarinia R, Shoja Razavi R et al. Current Nanoscience [J], 2012, 8(3): 402

20 Ahmadi-Pidani R, Shoja-Razavi R, Mozafarinia R et al. Optics and Lasers Engineering [J], 2012, 50: 780

21 Strano G, Hao L, Everson R M et al. Journal of Material Processing Technology[J], 2013, 213: 589 
22 Tsai P C, Lee J H, Chang C L. Surface and Coatings Technology [J], 2007, 202: 719

23 Ahmadi-Pidani R, Shoja-Razavi, Mozafarinia Reza et al. Material and Design[J], 2014, 57: 336

24 Antou G, Montavon G, Hlawka F et al. Journal of Thermal Spray Technology[J], 2004,13: 381

25 Ahmaniemi S, Tuominen J, Vuoristo P et al. Journal of Thermal
Spray Technology[J], 2002, 11: 320

26 Wang L, Wang Y, Sun X G et al. Material and Design[J], 2011, 32: 36

27 Hass D D, Slifka A J, Wadley H N G. Acta Material[J], 2001, 49: 973

28 Golosnoy I O, Cipitria A, Clyne T W. Journal of Thermal Spray Technology[J], 2009, 18 (5-6): 809

\title{
等离子喷涂“桩钉结构”YSZ 激光改性热障涂层的组织与性能
}

\author{
常 发 ${ }^{1,2,3}$, 周克崧 ${ }^{1,2,3}$, 佟 金金 ${ }^{2,3}$, 王 娇 ${ }^{2,3}$, 刘 敏 ${ }^{2,3}$, 康仲民 ${ }^{2,3}$ \\ (1. 华南理工大学, 广东 广州 510640) \\ (2. 广州有色金属研究院，广东 广州 510651) \\ (3. 广东省现代表面工程实验室, 广东 广州 510651)
}

\begin{abstract}
摘 要: 本试验采用大气等离子喷涂(APS)在含有 NiCoCrAlYTa 粘结层的镍基高温合金基体表面沉积氧化钇部分稳定氧化锆(YSZ)热障 涂层, 然后采用 Nd:YAG 的脉冲激光对热障涂层表面进行选择性激光表面改性处理, 最后对喷涂态和 “桩钉结构” 激光改性 YSZ 涂层 的组织与性能进行分析研究。结果表明：选择性激光表面改性形成的单元体表面粗粘度明显降低，表面的孔隙基本消除，同时形成了垂 直于表面的分割网状裂纹, 激光改性的 “桩钉结构” 单元体中还包含有柱状晶和等轴晶组织。XRD 分析发现, 喷涂态与 “桩钉结构” 单元体中都包含有非平衡四方相 $\mathrm{T}^{\prime}$, 然而经过激光改性后, 喷涂态中的单斜相 $\mathrm{M}$ 消失, $72^{\circ} \sim 76^{\circ}$ 范围中 $\mathrm{T}^{\prime}$ 峰明显增大。结果还发现，“桩 钉结构” 激光表面改性后, 喷涂态 YSZ 热障涂层的平均结合性能由 7.3 MPa 增大到 13.3 MPa; “桩钉结构” YSZ 涂层的隔热性能比喷 涂态的隔热性能有所下降, 这是由于激光表面改性导致陶瓷层组织结构改变所造成的。
\end{abstract}

关键词：YSZ；桩钉结构；激光表面改性；结合强度；隔热能力

作者简介: 常 发, 男, 1983 年生, 博士, 华南理工大学材料科学与工程学院, 广东 广州 510640, E-mail: cfzyzs_2011@163.com 